VOL. 3, NO. 1, Juni 2019

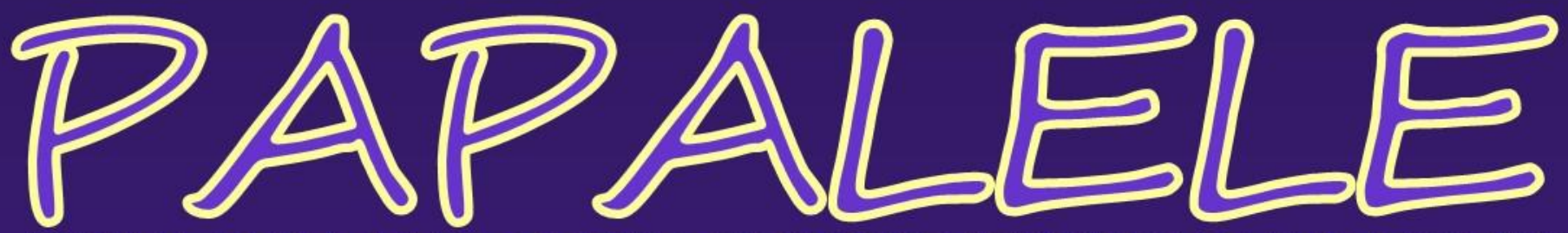
JURNAL PENELITIAN SOSIAL EKONOMI PERIKANAN DAN KELAUTAN

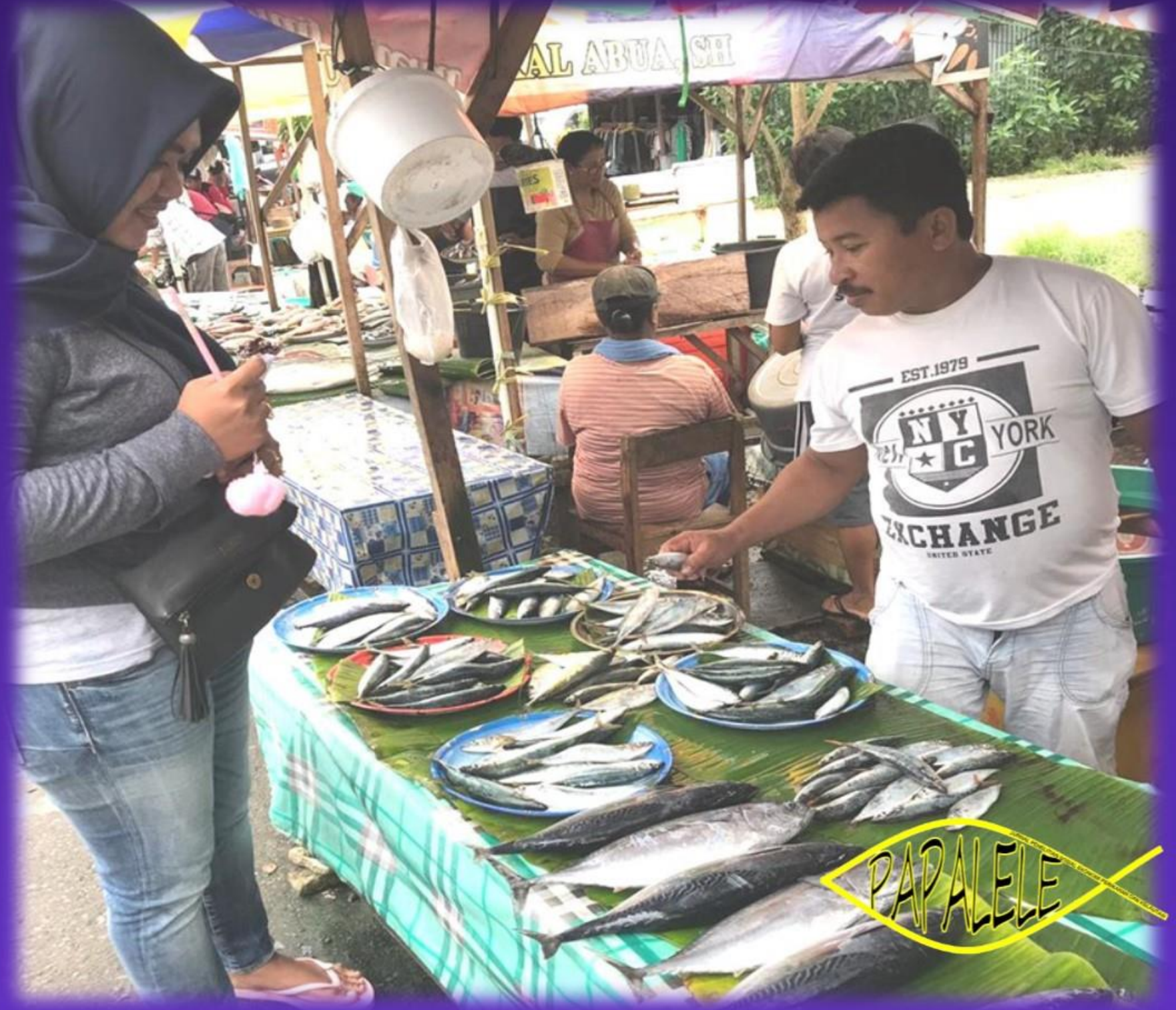

PAPALELE-JURNAL

PENELITIAN SOSIAL EKONOMI PERIKANAN DAN KELAUTAN

VOLUME 3

NOMOR

1

HALAMAN

JUNI 2019

ISSN

$1-51$

2580-0787

Diterbitkan oleh:

S 2 PROGRAM STUDI AGRIBISNIS PERIKANAN

mings FAKULTAS PERIKANAN DAN ILMU KELAUTAN

towing

UNIVERSITAS PATTIMURA 


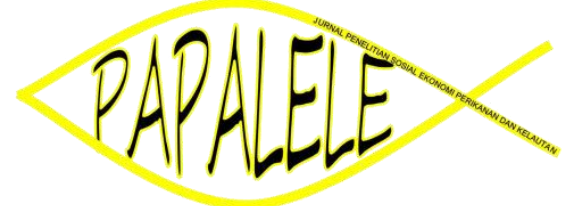

\section{JURNAL \\ PENELITIAN SOSIAL EKONOMI PERIKANAN DAN KELAUTAN}

\author{
PENANGGUNG JAWAB \\ Ketua Program Studi Sosial Ekonomi Perikanan \\ KETUA DEWAN REDAKSI \\ D. Bawole
}

RADAKTUR AHLI

V. Nikijuluw, M.S. Baskoro, J. Hiariej, F. Rieuwpassa, P. Wenno

REDAKTUR PELAKSANA

St. M. Siahainenia, R.L. Papilaya, Y. Lopulalan, Y.M.T.N. Apituley, V.J. Pical, W. Talakua, E. Talakua

PELAKSANA TATA USAHA

L.M. Soukotta, A. Ruban, K. Pattimukay, J. Sangaji, F. de Lima

PENERBIT

Program Studi Sosial Ekonomi Perikanan Jurusan Agrobisnis Perikanan

Fakultas Perikanan dan Ilmu Kelautan Universitas Pattimura

\section{ALAMAT REDAKTUR}

Program Studi Sosial Ekonomi Perikanan Jurusan Agrobisnis Perikanan Fakultas Perikanan dan Ilmu Kelautan Universitas Pattimura

Jln. Mr. Chr. Soplanit Poka-Ambon Telp. (0911) 379859. Fax 379196

PAPALELE merupakan jurnal penelitian ilmu sosial ekonomi perikanan dan kelautan yang menyajikan artikel tentang hasil penelitian yang berkaitan dengan bidang sosial ekonomi perikanan dan kelautan. Setiap naskah yang dikirim akan dinilai secara kritis oleh tim penilai yang relevan sebelum diterbitkan. Jurnal ini diterbitkan dua kali setahun, bulan Juni dan Desember. 


\section{KATA PENGANTAR}

Puji dan syukur kami panjatkan kepada Tuhan Yang Maha Esa atas rahmat-Nya. Jurnal PAPALELE, Jurnal penelitian Sosial Ekonomi Perikanan dan Kelautan kembali diterbitkan.

PAPALELE, Jurnal penelitian Sosial Ekonomi Perikanan dan Kelautan sesuai dengan Keputusan Lembaga Ilmu Pengetahuan Indonesia Nomor 0005.25800787/JI.3.1.SK.ISSN/2017.0529 Mei 2017 telah mengeluarkan nomor ISSN 2580-0787 untuk mulai penerbitan edisi volume 1 nomor 1, Juni 2017, dan sekarang melanjutkan perebitan untuk edisi volume 3 nomor 1, Juni 2019. Pada edisi ini, sama seperti edisi sebelumnya ditampilkan lima tulisan penelitian yang berkaitan dengan ilmu sosial ekonomi perikanan dan kelautan.

Dengan diterbitkannya jurnal ini, diharapkan dapat memberikan informasi ilmiah di bidang sosial ekonomi perikanan dan kelautan kepada pembaca. Saran dan masukan dari pembaca sangat diharapkan guna kesempurnaan penerbitan jurnal di waktu depan.

$\underline{\text { REDAKSI }}$ 


\section{DAFTAR ISI}

Halaman

KATA PENGANTAR

DAFTAR ISI ii

EFISIENSI TEKNIS DAN EKONOMI PERIKANAN TUNA HAND LINE DI NEGERI TIAL KABUPATEN MALUKU TENGAH

Oleh: Priscyllia Franetha Siahainenia, Dionisius Bawole, dan Willem Talakua $1-10$

ANALISIS KELAYAKAN USAHA KERAMBA JARING APUNG (KJA) DENGAN SISTEM MONOKULTUR DAN POLIKULTUR DI TANJUNG MARTHAFONS KOTA AMBON

Oleh: Tiffany Evangeline Leatemia

KELAYAKAN USAHA POLE AND LINE DI NEGERI HATIVE KECIL KOTA AMBON

Oleh: Ferdinan W. M. Haulussy

PRODUKTIVITAS DAN RESIKO USAHA PERIKANAN PURSE SEINE

DI NEGERI LATUHALAT

Oleh: Robert Frento Pattipeilohy dan Eygner Gerald Talakua

EFISIENSI DAN KEBERLANJUTAN USAHA PURSE SEINE DI KABUPATEN MALUKU TENGAH DAN KOTA AMBON

Oleh: Margie Wattimury 


\title{
KELAYAKAN USAHA KERAMBA JARING APUNG DENGAN SISTEM MONOKULTUR DAN POLIKULTUR DI TANJUNG MARTHAFONS KOTA AMBON
}

\section{FEASIBILITY OF FLOATING NET CAGE BUSINESS WITH MONOCULTURE AND POLICULTURE SYSTEMS IN TANJUNG MARTHAFONS AMBON}

\author{
Tiffany Evangeline Leatemia
}

\author{
Program Studi Agrobisnis Perikanan, \\ Fakultas Perikanan dan Ilmu Kelautan, Universitas Pattimura \\ Diterima 26 Agustus 2019, disetujui 7 Oktober 2019
}

\begin{abstract}
ABSTRAK
Budidaya ikan dalam keramba jaring apung dapat menggunakan sistem monokultur maupun polikultur. Sistem ini secara teknis telah dijalankan baik oleh pembudidaya di Tanjung Marthaalfons Perairan Teluk Ambon Bagian Dalam. Pengembangan suatu usaha budidaya ikan tidak hanya memperhatikan persoalan teknis, namun tingkat mortalitas ikan dan biaya operasional yang tinggi merupakan persoalan yang perlu diperhitungkan. Dengan demikian secara finansial usaha ini perlu dievaluasi, Melalui metode survei data dikumpulkan dari informan kunci. Data dianalisis dengan metode dekriptif kualitatif dan kuantitatif. Hasil penelitian menunjukkan bahwa usaha budidaya ikan dengan keramba jaring apung di Tanjung Marthaalfons Perairan Teluk Ambon Bagian Dalam secara finansial layak untuk dikembangkan. Namun, jika dibandingkan dengan upah minimum regional Provinsi Maluku, maka usaha dengan sistem polikultur dianggap lebih menguntungkan karena pendapatan berada di atas nilai upah minimum regional yaitu sebesar Rp 3.645.698/bulan. Selain itu, nilai return on investment dan revenue cost ratio usaha dengan sistem polikultur lebih tinggi dari sistem monokultur, dan payback period usaha dengan sistem polikultur lebih cepat dari sistem monokultur.
\end{abstract}

Kata kunci: budidaya, keramba jaring apung, kelayakan, monokultur, polikultur

\begin{abstract}
Fish culture in floating net cages can be done through monoculture and polyculture systems. Those systems have been carried out technically by farmers in Tanjung Marthaalfons Ambon Bay. The development of fish culture business does not only pay attention to technical issues, but also the level of fish mortality and operational costs. Thus, this business needs to be evaluated financially. Through survey, the data was collected from key informants, and analyzed in qualitative and quantitative descriptive method. The result shows that fish farming business with floating net cages in Tanjung Marthaalfons Ambon Bay in financially feasible to be developed. When the income is compared to regional minimum wage of Maluku, fish culture business with polyculture system is more profitable because the income is above the regional minimum wage value of $R p$. 3,645,698 / month. The value of return on investment and revenue cost ratio of fish culture with polyculture systems is higher than monoculture systems, and its payback period is faster than monoculture systems.
\end{abstract}

Key words: cultivation, floating net cages, feasibility, monoculture, polyculture 


\section{PENDAHULUAN}

Maluku merupakan salah satu Provinsi Kepulauan yang memiliki luas wilayah 581.376 $\mathrm{km}^{2}$ di mana $90 \%$ terdiri dari lautan yang mengandung sumberdaya perikanan sebesar 1.640.160 ton/tahun (Dinas Kelautan dan Perikanan, 2011). Peningkatan produksi perikanan Maluku bukan saja berasal dari subsektor perikanan tangkap, namun juga dari perikanan budidaya. Menurut Murachman $d k k$ (2010), usaha ke arah budidaya ikan di perairan umum sangat diperlukan sebagai penyeimbang dan pembantu pemenuhan produksi ikan yang selama ini diperoleh dari hasil penangkapan yang cenderung semakin menurun. Peningkatan produksi perikanan dapat dilakukan dengan kegiatan budidaya ikan di keramba jaring apung (KJA).

Budidaya ikan dalam KJA dapat menggunakan sistem monokultur maupun polikultur. Monokultur merupakan pola budidaya satu jenis komoditas, sedangkan polikultur merupakan pola budidaya 2 jenis komoditas berbeda dengan kebiasaan makan yang berbeda dan bertujuan untuk mendapatkan hasil yang lebih dengan biaya yang rendah (Murachman $d k k, 2010$ ).

Tanjung Marthalfons merupakan lokasi yang digunakan untuk melakukan kegiatan budidaya karena terletak di perairan Teluk Ambon Bagian Dalam (TAD), yang merupakan kawasan peruntukan budidaya perikanan Kota Ambon. Berdasarkan pengamatan di lapangan, secara teknis usaha budidaya baik untuk sistem monokultur maupun sistem polikultur sudah efektif. Hal ini ditunjukkan dengan adanya pertumbuhan ikan yang selalu meningkat selama siklus budidaya (6-8 bulan). Di lain sisi, pengembangan suatu usaha bukan hanya memperhatikan persoalan teknis, namun tingkat mortalitas ikan dan biaya operasional yang tinggi merupakan persoalan yang perlu diperhitungkan. Dengan demikian secara finansial perlu dievaluasi, diantara kedua sistem budidaya, manakah yang lebih layak untuk dikembangkan kedepannya. Oleh karena itu, penelitian ini perlu dilakukan untuk mengkaji secara finansial, kelayakan usaha keramba jaring apung dengan sistem monokultur dan polikultur di Tanjung Marthafons Kota Ambon.

\section{METODE PENELITIAN Metode Dasar Penelitian}

Metode yang digunakan dalam penelitian ini adalah metode survei. Survei adalah suatu penyelidikan yang diadakan untuk memperoleh fakta-fakta dari gejala-gejala yang ada dan mencari keterangan secara faktual, baik tentang institusi sosial, ekonomi, atau politik dari suatu kelompok ataupun daerah (Nazir, 2011).

\section{Metode Pengumpulan Data}

Ada 2 jenis data yang digunakan untuk menunjang penelitian ini, yaitu:

1. Data Primer: Pengumpulan data primer dilakukan dengan metode survei, yaitu dengan melakukan observasi, wawancara terstruktur dengan menggunakan kuesioner, serta dokumentasi. Data primer yang dikumpulkan meliputi teknik budidaya, biaya investasi, biaya tetap, biaya operasional, sumber modal, volume dan nilai produksi, harga jual serta tujuan pasar.

2. Data Sekunder: Pengumpulan data sekunder melalui instansi-instansi terkait dan studi pustaka yang menunjang penelitian ini. Data sekunder yang dikumpulkan meliputi keadaan umum lokasi penelitian, perkembangan produksi perikanan, dan tingkat suku bunga tahunan pada saat penelitian berlangsung.

\section{Informan Kunci}

Dalam penelitian ini, informan kunci (key informan) yang digunakan adalah pemilik yang sekaligus bertindak sebagai pengelola usaha budidaya ikan dengan sistem monokultur dan polikultur di Tanjung Marthafons yang memahami dan mengetahui perkembangan budidaya.

\section{Metode Analisis Data}

Data yang dikumpulkan kemudian dianalisis dengan menggunakan metode deskripstif kualitatif dan deskriptif kuantitatif yang meliputi perhitungan sebagai berikut:

a. Biaya Total 
$\mathrm{TC}=\mathrm{TFC}+\mathrm{TVC}$

dimana :

$\mathrm{TC}=$ Total Biaya/Total Cost (Rp/Siklus)

TFC $=$ Total Biaya Tetap/Total Fixed Cost (Rp/Siklus)

$\mathrm{TVC}=$ Total Biaya Variabel/Total Variable Cost (Rp/Siklus)

b. Total Penerimaan

$\mathrm{TR}=\mathrm{P} \times \mathrm{Q}$

dimana :

$\mathrm{TR}=$ Total Penerimaan/Total Revenue (Rp/Siklus)

$\mathrm{P}=$ Harga/Price $(\mathrm{Rp} / \mathrm{Kg})$

$\mathrm{Q}=$ Produksi $/$ Quantity (Kg/Siklus)

c. Pendapatan Usaha

$\boldsymbol{\pi}=\mathrm{TR}-\mathrm{TC}$

dimana :

$\boldsymbol{\Pi}=$ Pendapatan/Keuntungan Usaha (Rp/Siklus)

$\mathrm{TR}=$ Penerimaan $/$ Total Revenue (Rp/Siklus)

$\mathrm{TC}=$ Biaya Total/Total Cost (Rp/Siklus)

d. Biaya Penyusutan

$\mathrm{DP}=\frac{c-s}{n}$

dimana :

$\mathrm{DP}=$ Nilai depresiasi/Penyusutan (Rp/Tahun)

$\mathrm{C}=$ Harga Beli/Cost (Rp)

$\mathrm{S}=$ Nilai Sisa/Salvage $(\mathrm{Rp})$

$\mathrm{n}=$ Perkiraan Umur Ekonomis Barang (Tahun)

e. Break Even Point (BEP) atau Titik Impas

$\left.\operatorname{BEP}(\mathrm{Q})=\frac{F C}{P-V C / Q}\right)$

$\operatorname{BEP}(\mathrm{P})=\frac{F C}{1-V C / S}$

dimana :

$\operatorname{BEP}(\mathrm{Q})=$ Titik Impas (Dalam Unit)

BEP $(\mathrm{P})=$ Titik Impas (Dalam Rupiah)

$\mathrm{FC}=$ Biaya Tetap/Fixed Cost (Rp/Siklus)

$\mathrm{VC}=$ Biaya Variabel/Variable Cost (Rp/Siklus)

$\mathrm{P} \quad=$ Harga $/$ Price $(\mathrm{Rp} / \mathrm{Kg})$

$\mathrm{Q}=$ = Produksi/Quantity (Kg/Siklus)

$\mathrm{S} \quad=$ Hasil Penjualan

f. Return on Investment (ROI)

$$
\mathrm{ROI}=\frac{\text { Keuntungan }}{\text { Investasi }} \times 100 \%
$$

g. Payback Period (PP)

$$
\mathrm{PP}=\frac{\text { Investasi }}{\text { Kas Bersih/Tahun }} \times 1 \text { Tahun }
$$

h. Revenue Cost Ratio (R/C Ratio)

$$
\mathrm{R} / \mathrm{C} \text { Ratio }=\frac{T R}{T F C+T V C} \text {. }
$$

dimana:

TR = Total Penerimaan $/$ Total Revenue (Rp/Siklus)

TFC $=$ Total Biaya Tetap/Total Fixed Cost (Rp/Siklus)

$\mathrm{TVC}=$ Total $\quad$ Biaya $\quad$ Variabel/Total Variable Cost (Rp/Siklus)

\section{HASIL DAN PEMBAHASAN \\ Teknik Budidaya dengan KJA}

Teknik budidaya di lokasi penelitian kurang lebih sama dengan teknik budidaya pada umumnya di mana proses budidaya dimulai dengan pemilihan lokasi untuk penempatan KJA. Setelah itu dilanjutkan dengan tahap persiapan berupa pengecekan sarana dan prasarana budidaya. Dilanjutkan dengan tahap penebaran benih yang dilakukan pada pagi hari atau sore hari (saat suaca teduh). Luas keramba yang digunakan dalam kegiatan budidaya dengan sistem monokultur adalah 9,80 m X $3 \mathrm{~m} \mathrm{X} 3 \mathrm{~m}$ dan sistem polikultur adalah 9,80 m X 3 m X 7 m. Berbeda dengan KJA pada umumnya, KJA pada lokasi penelitian ini hanya terdiri dari 3 kotak dengan sistem jaring lepas untuk menjaga ruang gerak ikan dan pada saat ikan mencapai ukuranukuran tertentu, tidak perlu dikurangi kepadatannya dan dipindahkan ke kolam yang lain.

Benih yang ditebar adalah benih kerapu cantang untuk sitem monokultur dan pada sistem polikultur, benih yang ditebar adalah kerapu cantang dan bubara. Sebelum benih ditebar, dilakukan proses aklimatisasi. Setelah itu, ikan diberi pakan alami berupa ikan rucah dan pakan buatan berupa pelet dengan frekuensi pemberian pakan $2 \mathrm{x}$ sehari yaitu pada pagi dan sore hari. Proses pemberian pakan dilakukan hanya melalui kolam bagian tengah untuk monokultur, dan sistem polikultur, pemberian pakan untuk ikan bubara yang berada pada jaring lapisan bawah dilakukan dengan 
mengangkat salah satu ujung jaring bagian atas Proses pembesaran berlangsung selama 6-8 bulan untuk kemudian dipanen yang disesuaikan dengan permintaan pasar.

\section{Pemasaran}

Pada usaha KJA baik untuk sistem monokultur maupun polikultur, umumnya pemilik-pemilik restoran di Kota Ambon selaku konsumen telah melakukan transaksi dan kemudian langsung membeli pada lokasi budidaya. Sedangkan untuk konsumen yang berasal dari warung kaki lima, pembudidaya selaku produsen yang mengantarkan langsung ke tempat konsumen. Sehingga dapat diartikan bahwa untuk saluran pemasaran, usaha KJA baik untuk sistem monokultur maupun sistem polikultur tidak menggunakan jasa perantara.

\section{Struktur Biaya}

Penggunaan Modal Awal

Modal yang digunakan baik untuk usaha KJA dengan sistem monokultur maupun sistem polikultur berasal dari modal sendiri (pribadi).

\section{Tabel 1. Komponen Biaya Investasi Usaha KJA di Tanjung Marthafons}

\begin{tabular}{|c|c|c|c|c|c|}
\hline \multirow[b]{2}{*}{ No. } & \multirow[b]{2}{*}{ Barang Investasi } & \multicolumn{2}{|c|}{ Nilai Investasi (Rp) } & \multicolumn{2}{|c|}{ Persentase (\%) } \\
\hline & & $\begin{array}{c}\text { Sistem } \\
\text { Monokultur }\end{array}$ & $\begin{array}{c}\text { Sistem } \\
\text { Polikultur }\end{array}$ & $\begin{array}{c}\text { Sistem } \\
\text { Monokultur }\end{array}$ & $\begin{array}{c}\text { Sistem } \\
\text { Polikultur }\end{array}$ \\
\hline 1. & Keramba & 13.091 .000 & 17.591 .000 & 77,7 & 82,4 \\
\hline 2. & Timbangan & 100.000 & 100.000 & 0,6 & 0,5 \\
\hline 3. & Freezer & 1.250 .000 & 1.250 .000 & 7,4 & 5,9 \\
\hline 4. & $\begin{array}{l}\text { Mesin Penyemprot } \\
\text { Jaring }\end{array}$ & 750.000 & 750.000 & 4,5 & 3,5 \\
\hline 5. & Perahu & 1.500 .000 & 1.500 .000 & 8,9 & 7,0 \\
\hline 6. & Peralatan Pembantu & 155.000 & 155.000 & 0,9 & 0,7 \\
\hline & Total & 16.846.000 & 21.346.000 & 100 & 100 \\
\hline
\end{tabular}

Sumber: Data Primer, diolah 2019

Berdasarkan Tabel 1, dapat dilihat bahwa total biaya investasi untuk KJA sistem monokultur sebesar Rp 16.846.000 dan untuk KJA dengan sistem polikultur sebesar Rp 21.346.000. Keramba merupakan komponen biaya investasi paling besar yaitu untuk sistem monokultur sebesar $77,7 \%$ dari total biaya investasi dan untuk sistem polikultur sebesar $82,4 \%$ dari total biaya investasi. Keramba terdiri dari rakit, jaring, pelampung dan pemberat serta peralatan pembantu yang digunakan dalam usaha ini meliputi ember plastik dan gayung. Barang modal lain seperti timbangan, freezer, mesin penyemprot jaring dan perahu digunakan secara bersama-sama pada kedua unit usaha tersebut karena pemiliknya sama sehingga untuk mengidentifikasi nilai investasinya maka nilai setiap barang modal dibagi dua.

\section{Biaya Tetap}

Biaya-biaya yang digolongkan ke dalam biaya tetap usaha KJA di Tanjung Marthafons adalah penyusutan dan pemeliharaan, dimana biaya pemeliharaan hanya dikeluarkan jika terjadi kerusakan pada barang modal.

Tabel 2. Pengeluaran Biaya Tetap menurut Jenis Usaha

\begin{tabular}{lccc}
\hline \multirow{2}{*}{ Jenis Usaha } & \multicolumn{2}{c}{ Biaya Tetap (Rp/Siklus) } & \multirow{2}{*}{ Jumlah (Rp) } \\
\cline { 2 - 3 } & Penyusutan & Pemeliharaan & \\
\hline Sistem Monokultur & 3.145 .403 & 175.000 & 3.320 .403 \\
Sistem Polikultur & 3.752 .025 & 166.667 & 3.918 .692 \\
\hline
\end{tabular}

Sumber: Data Primer, diolah 2019

Berdasarkan Tabel 2, dapat dilihat bahwa biaya tetap untuk unit usaha KJA dengan sistem monokultur rata-rata sebesar $\mathrm{Rp}$ 3.320.403/siklus dimana biaya penyusutan rata- 
rata sebesar Rp 3.145.403/siklus dan biaya pemeliharaan rata-rata sebesar $\mathrm{Rp}$ 175.000/siklus, sementara sistem polikultur rata-rata sebesar $\mathrm{Rp}$ 3.918.692/siklus dimana biaya penyusutan rata-rata sebesar $\mathrm{Rp}$ 3.752.025/siklus dan biaya pemeliharaan ratarata sebesar Rp 166.667/siklus.

Biaya Variabel

Komponen biaya variabel dari usaha KJA di lokasi penelitian mencakup biaya untuk pembelian benih, pakan berupa pelet dan ikan rucah, upah tenaga kerja, transportasi dan listrik.

Tabel 3. Pengeluaran Biaya Investasi Menurut Jenis Usaha

\begin{tabular}{|c|c|c|c|c|c|c|c|}
\hline \multirow[b]{2}{*}{ Jenis Usaha } & \multicolumn{6}{|c|}{ Biaya Variabel (Rp/Siklus) } & \multirow[b]{2}{*}{ Total } \\
\hline & Benih & Pelet & $\begin{array}{c}\text { Ikan } \\
\text { Rucah }\end{array}$ & $\begin{array}{c}\text { Upah } \\
\text { Tenaga } \\
\text { Kerja }\end{array}$ & Transportasi & Listrik & \\
\hline $\begin{array}{l}\text { Sistem } \\
\text { Monokultur }\end{array}$ & 9.000 .000 & 1.072 .000 & 4.110 .000 & 4.500 .000 & 490.000 & 100.000 & 19.272 .000 \\
\hline $\begin{array}{l}\text { Sistem } \\
\text { Polikultur }\end{array}$ & 11.083 .333 & 1.920 .000 & 12.716 .000 & 6.750 .000 & 883.333 & 100.000 & 33.452 .667 \\
\hline
\end{tabular}

Sumber: Data Primer, diolah 2019

Berdasarkan Tabel 3, dapat dilihat bahwa biaya variabel untuk unit usaha KJA dengan sistem monokultur rata-rata sebesar Rp 19.272.000/siklus dan untuk sistem polikultur rata-rata sebesar Rp 33.452.667/siklus. Biaya yang dikeluarkan untuk pakan baik itu pakan alami maupun pakan buatan dipengaruhi oleh tingkat produksi pada masing-masing siklus sehingga terjadi perubahan biaya pakan pada tiap siklus, sedangkan biaya transportasi, perubahan biaya pada tiap siklus dipengaruhi oleh frekuensi distribusi hasil produksi ke konsumen pada tiap siklus.

\section{Penerimaan dan Pendapatan}

Penerimaan merupakan nilai yang diterima dari penjualan suatu produk, yang merupakan hasil perkalian antara produksi yang diperoleh dengan harga jual produk. Pendapatan atau keuntungan terbagi 2, yaitu keuntungan sebelum pajak (earning before tax) merupakan nilai keuntungan yang diperoleh usaha sebelum dikurangi dengan pajak (10\%) dan keuntungan sesudah pajak (earning after tax) atau dapat juga disebut sebagai keuntungan bersih (net revenue) merupakan selisih antara nilai keuntungan sebelum pajak dikurangi dengan pajak.

Tabel 4. Penerimaan, Pengeluaran dan Keuntungan Usaha menurut Jenis Usaha

\begin{tabular}{cccccccc}
\hline \multirow{2}{*}{ Jenis Usaha } & $\begin{array}{c}\text { Penerimaan } \\
\text { (Rp/Siklus) }\end{array}$ & \multicolumn{2}{c}{$\begin{array}{c}\text { Pengeluaran (Rp/Siklus) } \\
\text { Biaya }\end{array}$} & $\begin{array}{c}\text { Biaya } \\
\text { Variabel }\end{array}$ & Tetap & Total & \multicolumn{2}{c}{$\begin{array}{c}\text { Keuntungan } \\
\text { Sebelum } \\
\text { Pajak }\end{array}$} & $\begin{array}{c}\text { Sesudah } \\
\text { Pajak }\end{array}$ \\
\hline $\begin{array}{c}\text { Sistem } \\
\text { Monokultur } \\
\begin{array}{c}\text { Sistem } \\
\text { Polikultur }\end{array}\end{array}$ & 43.384 .000 & 19.272 .000 & 3.320 .403 & 22.592 .403 & 20.791 .597 & 18.712 .437 \\
\hline
\end{tabular}

Sumber: Data Primer, diolah 2019

Berdasarkan Tabel 4, dapat dilihat bahwa penerimaan rata-rata usaha KJA dengan sistem monokultur sebesar Rp 43.384.000/siklus dan sistem polikultur sebesar Rp 73.828.333/siklus. Perbedaan penerimaan tiap siklus diakibatkan oleh perbedaan produksi yang dipengaruhi oleh tingkat mortalitas ikan yang dipeliharaan
Berdasarkan tabel diatas pula dapat dilihat bahwa keuntungan rata-rata sebelum pajak yang diperoleh usaha KJA dengan sistem monokultur sebesar Rp 20.791.597/siklus dan sistem polikultur sebesar Rp 36.456.975/siklus yang diperoleh melalui selisih antara penerimaan rata-rata dengan total pengeluaran rata-rata. Keuntungan bersih yang didapatkan usaha KJA dengan sistem monokultur rata-rata 
sebesar Rp 18.712.437/siklus yang diperoleh melalui selisih antara keuntungan sebelum pajak dengan pajak (10\%) atau $\mathrm{Rp}$ 2.079.160/bulan yang diperoleh dengan cara membagi keuntungan bersih dengan jumlah bulan di dalam 1 siklus budidaya. Jika dibandingkan dengan UMR (upah minimum regional) Provinsi Maluku, maka keuntungan per bulan usaha KJA dengan sistem monokultur ini masih berada di bawah UMR yaitu sebesar Rp 2.400.664/bulan. Untuk sistem polikultur rata-rata penerimaan bersih sebesar $\mathrm{Rp}$ 32.811.278/siklus atau Rp 3.645.698/bulan yang jika dibandingkan dengan UMR, maka keuntungan per bulan usaha KJA dengan sistem polikultur berada di atas UMR. Dengan kata lain, usaha KJA dengan sistem polikultur lebih menguntungkan untuk dikembangkan dibandingkan dengan usaha KJA dengan sistem monokultur.

\section{Analisis Kelayakan Finansial Usaha}

Dalam penelitian ini, analisis yang digunakan adalah analisis finansial dengan menggunakan pendekatan non-time value of money atau mengabaikan nilai waktu dari uang.

\section{Break Even Point (BEP)}

Dengan mengetahui titik impas, suatu usaha dapat mengetahui pada volume penjualan sebanyak apa dan pada tingkat harga berapa perusahaan mencapai titik impas yaitu tidak mengalami kerugian tetapi juga belum mengalami keuntungan sehingga apabila penjualan melebihi titik impas maka perusahaan tersebut mulai memperoleh keuntungan.

Tabel 5. BEP Usaha KJA di Tanjung Marthafons

\begin{tabular}{crrr}
\hline \multirow{2}{*}{ Uraian } & \multicolumn{1}{c}{ Sistem } & \multicolumn{2}{c}{ Sistem Polikultur } \\
\cline { 3 - 4 } & Monokultur & Ikan Kerapu Cantang & Ikan Bubara \\
\hline BEP Harga (Rp/Kg) & 44.299 & 39.585 & 42.187 \\
BEP Produksi & 266 & 235 & 232 \\
(Kg/Siklus) & &
\end{tabular}

Sumber: Data Primer, diolah 2019

Berdasarkan Tabel 5, dapat dilihat dapat dilihat bahwa usaha KJA dengan sistem monokultur akan mencapai titik impas atau break even point, jika produk dijual dengan

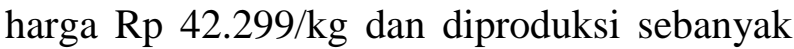
$266 \mathrm{~kg} /$ siklus. Berdasarkan wawancara yang dilakukan dengan pembudidaya, produk dijual dengan harga $\mathrm{Rp} 85.000 / \mathrm{kg}$ dan diproduksi rata-rata sebanyak 501,4 kg/siklus. Usaha KJA dengan sistem polikultur akan mencapai titik impas jika ikan kerapu cantang dijual dengan harga $\mathrm{Rp} 39.585 / \mathrm{kg}$ dan diproduksi sebanyak
$235 \mathrm{~kg} /$ siklus sementara ikan bubara dijual dengan harga $\mathrm{Rp} 42.187 / \mathrm{kg}$ dan diproduksi sebanyak $232 \mathrm{~kg} / \mathrm{siklus}$. Berdasarkan wawancara yang dilakukan dengan pembudidaya, ikan kerapu cantang dijual dengan harga $\mathrm{Rp} 85.000 / \mathrm{kg}$ dan diproduksi rata-rata sebanyak 505,3 kg/siklus dan ikan bubara dijual dengan harga $\mathrm{Rp} 75.000 / \mathrm{kg}$ dan diproduksi rata-rata sebanyak 411,7 kg/siklus. Jadi, dapat disimpulkan bahwa usaha KJA di lokasi penelitian sudah mengalami keuntungan dan layak untuk dikembangkan. 


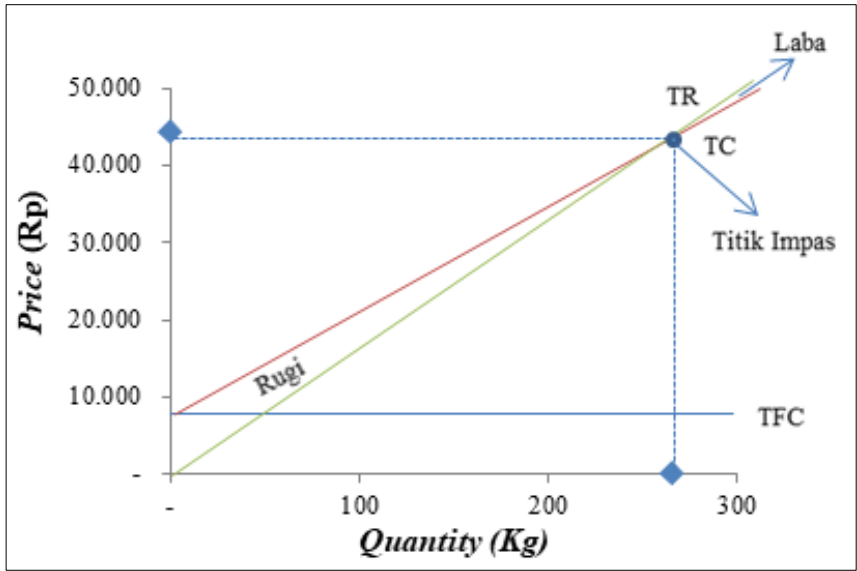

Gambar 1. Kurva BEP Usaha KJA Sistem Monokultur

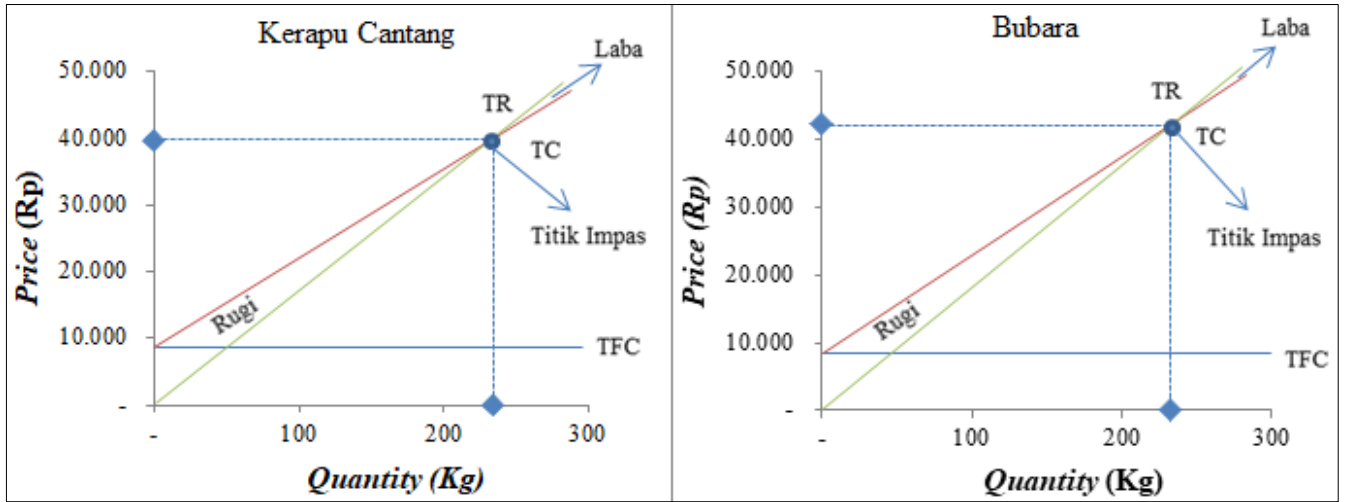

Gambar 2. Kurva BEP Usaha KJA Sistem Polikultur

Biaya tetap (fixed cost, FC) sejajar dengan produksi (quantity, Q) disebabkan karena pengeluaran untuk biaya tetap bersifat statis walaupun produksi berubah-ubah, sedangkan biaya variabel (variable cost, VC) sifatnya linear terhadap produksi, artinya biaya variabel dinamis terhadap kegiatan produksi. Garis total penerimaan (total revenue, TR) merupakan fungsi dari produksi, dengan persamaan matematis $T R=f(Q)$ yang sifat pergerakannya positif atau searah. Berdasarkan persamaan tersebut, TR merupakan variabel terikat (dependen) dan $\mathrm{Q}$ merupakan variabel bebas (independen), yang artinya ketika produksi meningkat maka total penerimaan juga akan meningkat dan sebaliknya. Biaya total (total cost, TC) merupakan penjumlahan antara FC dan VC. Dalam pasar persaingan sempurna, harga per satuan komoditas yang dijual mengikuti harga yang terjadi di pasar sehingga apabila harga per satuan komoditasnya adalah $\mathrm{P}$ (price) dan produsen menjual sebanyak Q maka TR = P x Q. Dengan demikian, jika harga jual tidak mengalami

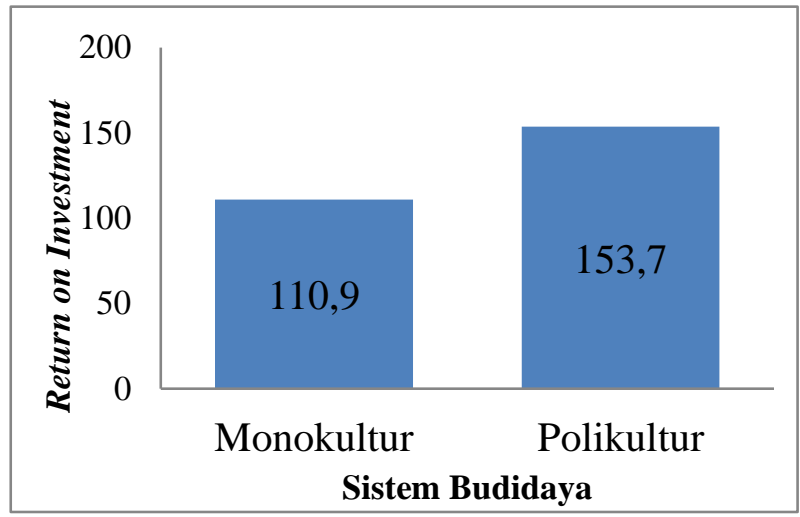

perubahan, maka TR berbentuk garis lurus yang bermula dari titik original. Daerah di atas titik BEP merupakan daerah laba dan daerah di bawah titik BEP merupakan daerah rugi (Firdaus, 2012).

\section{Return on Investment (ROI)}

Dengan analisis ROI, perusahaan dapat mengukur sampai seberapa besar kemampuannya dalam mengembalikan modal yang ditanamkan. 


\section{Gambar 3. Nilai ROI Usaha KJA di Tanjung Marthafons}

Berdasarkan Gambar 3, dapat dilihat nilai ROI tertinggi berada pada unit usaha KJA dengan sistem polikultur yaitu sebesar 153,7\% dan nilai ROI terendah berada pada unit usaha KJA dengan sistem monokultur yaitu sebesar $110,9 \%$. Berdasarkan kriteria, tingginya nilai ROI menunjukkan kemampuan usaha dalam mengembalikan modal awal. Jika dibandingkan nilai investasi dan pendapatan yang diperoleh kedua unit usaha tersebut, usaha KJA dengan sistem polikultur dinilai lebih menguntungkan karena dengan nilai investasi yang tidak berbeda jauh dengan usaha KJA sistem

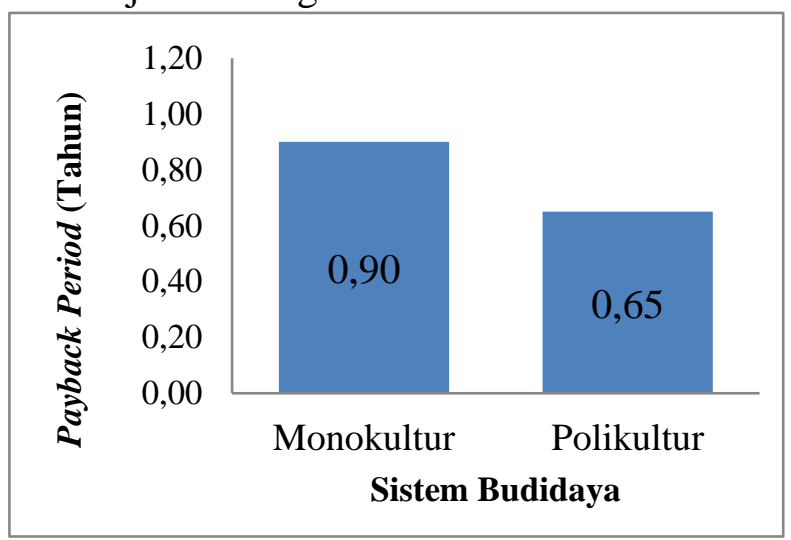

Gambar 4. Nilai PP dan Discounted PP Usaha KJA di Tanjung Marthafons

Berdasarkan Gambar 4, dapat dilihat bahwa berdasarkan jenis usaha yang dijalankan, nilai PP yang dihasilkan adalah 0,9 untuk sistem monokultur dan 0,65 untuk sistem polikultur. Hal ini berarti bahwa usaha KJA dengan sistem monokultur dapat mengembalikan modal awal dalam jangka waktu 11 bulan sedangkan usaha KJA dengan sistem polikultur dapat mengembalikan modal awal dalam jangka waktu 8 bulan. Untuk mengatasi kelemahan analisis PP karena mengabaikan nilai waktu dari uang atau time value of money, maka metode perhitungan $\mathrm{PP}$ dapat diperbaiki dengan mem-present valuekan nilai keuntungan bersih menggunakan DF 7\% berdasarkan tingkat suku bunga tahunan yang berlaku pada saat penelitian berlangsung. Cara ini disebut sebagai discounted payback period. Lamanya pengembalian modal untuk suatu usaha berbanding lurus dengan besarnya pendapatan yang diperoleh. Jika pendapatan yang diperoleh suatu usaha tinggi, maka periode pengembalian modal awal usaha monokultur, usaha ini dapat menghasilkan keuntungan yang jauh lebih besar.

\section{Payback Period (PP)}

Payback period merupakan metode yang digunakan untuk menghitung lama periode yang diperlukan untuk mengembalikan modal yang telah diinvestasikan dari aliran kas masuk (Proceeds) tahunan yang dihasilkan oleh proyek investasi tersebut. Kriteria kelayakan dari penerimaan investasi menggunakan metode payback period adalah suatu investasi akan dikatakan layak jika payback period lebih pendek dibandingkan dengan payback period maximum yang diharapkan oleh pengusaha.

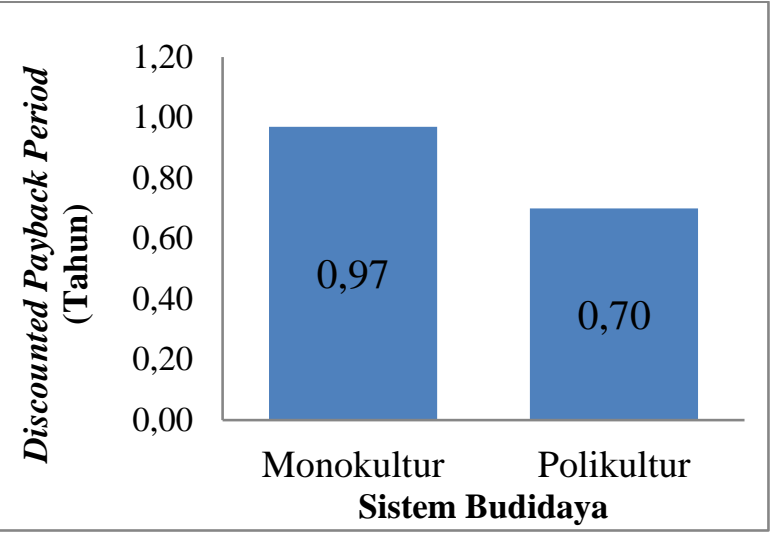

tersebut akan lebih cepat dan sebaliknya. Jika nilai PP yang diperoleh dibandingkan dengan payback period maximum yang diharapkan oleh pembudidaya yaitu selama 5 tahun dengan mempertimbangkan umur ekonomis usaha, maka baik usaha monokultur maupun polikultur layak untuk dikembangkan karena nilai PP yang diperoleh lebih rendah dari nilai payback period maximum yang diharapkan oleh pembudidaya, namun usaha KJA dengan sistem polikultur dianggap lebih layak karena memiliki periode pengembalian modal awal yang lebih cepat dibandingkan dengan sistem monokultur.

\section{Revenue Cost Ratio (R/C Ratio)}

Menurut Mamondol (2016), revenue cost ratio atau $\mathrm{R} / \mathrm{C}$ ratio merupakan perbandingan antara penerimaan suatu usaha dengaan biaya yang dikorbankan. Suatu usaha akan dikatakan layak apabila nilai $\mathrm{R} / \mathrm{C}$ ratio lebih dari 1. Hal ini menggambarkan bahwa semakin tinggi nilai $\mathrm{R} / \mathrm{C}$ ratio maka semakin 
tinggi pula tingkat keuntungan yang akan diperoleh suatu usaha.

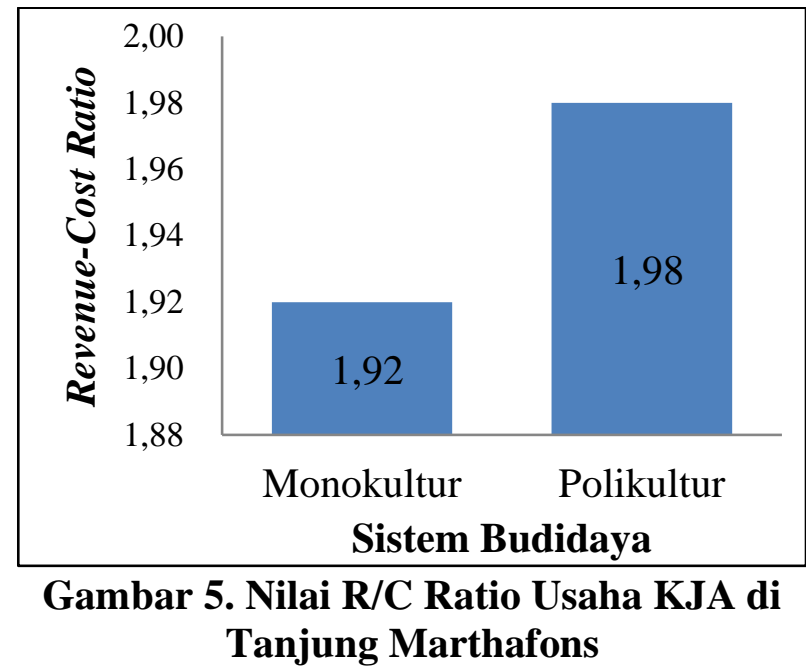

Penerimaan usaha yang besar tidak selalu mencerminkan bahwa tingkat efisiensi ekonomi dari usaha tersebut juga tinggi. Guna mengetahui efisiensi ekonomi suatu usaha dapat digunakan analisis R/C. Berdasarkan gambar 5, dapat dilihat bahwa nilai $\mathrm{R} / \mathrm{C}$ untuk usaha KJA dengan sistem monokultur adalah 1,92 dan usaha KJA dengan sistem polikultur adalah 1,98. Jika dibandingkan dengan kriteria kelayakan suatu usaha yaitu nilai $\mathrm{R} / \mathrm{C}$ harus lebih dari 1, maka kedua usaha di lokasi penelitian layak untuk dikembangkan karena nilai yang diperoleh lebih besar dari kriteria kelayakan yang ditetapkan. Nilai R/C lebih dari 1 berarti bahwa jumlah penerimaan yang diterima lebih besar dari total biaya yang dikeluarkan. Nilai R/C yang diperoleh menunjukkan bahwa setiap Rp 1 biaya yang dikeluarkan akan menghasilkan penerimaan sebesar Rp 1,92 untuk usaha KJA dengan sistem monokultur dan $\mathrm{Rp} 1$ biaya yang dikeluarkan akan menghasilkan penerimaan sebesar Rp 1,98 untuk usaha KJA dengan sistem polikultur. Jika dilihat dari nilai R/C ratio yang diperoleh, usaha KJA dengan sistem polikultur dianggap lebih menguntungkan karena menunjukkan nilai $\mathrm{R} / \mathrm{C}$ ratio yang lebih tinggi dimana hal ini berarti bahwa tingkat efisiensi ekonomi usaha KJA dengan sistem polikultur lebih tinggi dari tingkat efisiensi usaha KJA dengan sistem monokultur meskipun dijalankan pada luasan lahan budidaya yang sama.

\section{KESIMPULAN}

1. Teknik budidaya ikan dalam KJA di Tanjung Marthafons kurang lebih sama dengan teknik budidaya ikan dalam KJA pada umumnya. Namun, konstruksi jaring untuk kedua sistem ini sudah dimodifikasi untuk menyesuaikan dengan kegiatan budidaya yang dilakukan Ukuran KJA untuk sistem monokultur adalah 9,8 $\mathrm{m} \mathrm{X} 3$ $\mathrm{m} X 3 \mathrm{~m}$ dan untuk sistem polikultur adalah 9,80 m X 3 m X 7 m.

2. Biaya tetap, biaya variabel yang dikeluarkan usaha KJA dengan sistem monokultur dan polikultur rata-rata sebesar $\mathrm{Rp}$ 3.320.403/siklus dan Rp 3.918.692/siklus; Rp 19.272.000/siklus dan Rp 33.452.666/siklus. Berdasarkan biaya yang dikeluarkan, usaha memperoleh keuntungan rata-rata sebesar Rp 18.681.837/siklus dan Rp 32.808.278/siklus.

3. Berdasarkan kriteria penilaian investasi dengan pendekatan non-time value of money, dapat disimpulkan bahwa usaha KJA di lokasi penelitian secara finansial layak untuk dikembangkan. Namun, jika dibandingkan dengan UMR Provinsi Maluku, maka usaha KJA dengan sistem polikultur dianggap lebih menguntungkan karena pendapatan KJA dengan sistem polikultur berada di atas nilai UMR yaitu sebesar Rp 3.645.698/bulan. Selain itu, nilai ROI dan R/C Ratio usaha KJA dengan sistem polikultur lebih tinggi dari sistem monokultur dan PP usaha KJA dengan sistem polikultur lebih cepat dari sistem monokultur.

\section{SARAN}

1. Berdasarkan perhitungan kriteria kelayakan finansial terhadap kedua jenis usaha tersebut, usaha KJA dengan sistem polikultur dinilai lebih layak untuk dikembangkan karena dengan perbedaan sedikit biaya investasi dapat mendatangkan keuntungan yang jauh lebih besar sehingga pola budidaya dengan sistem polikultur dapat dijadikan contoh bagi pembudidaya yang lain.

2. Disarankan agar penelitian selanjutnya dapat menganalisis kelayakan usaha dari aspek pasar, teknis dan produk, lokasi dan letak, 
hukum, manajemen dan pengelolaan serta lingkungan.

\section{DAFTAR PUSTAKA}

[DKP] Dinas Kelautan dan Perikanan Provinsi Maluku. 2011. Statistik Perikanan Provinsi Maluku. Pemerintah Provinsi Maluku.

Kasmir dan Jakfar. 2017. Studi Kelayakan Bisnis. Penerbit: Kencana. Jakarta.

Mamondol, M. R. 2016. Analisis Kelayakan Ekonomi Usaha Tani Padi Sawah di Kecamatan Pamona Puselemba. Jurnal Envira Vol. 1 (2) Desember 2016.

Murachman, Hanani, N., Soemarno, Muhammad, S. 2010. Model Polikultur Udang Windu (Penaeus monodon), Ikan Bandeng (Chanos chanos) dan Rumput Laut Secara Tradisional. Jurnal Pembangunan dan Alam Lestari. Vol. 1 (1) Tahun 2010 ISSN 2087-3522.

Nazir. 2011. Metode Penelitian. Cetakan 6. Penerbit Ghalia Indonesia. Bogor. 


\section{PEDOMAN PENULISAN}

\section{Pedoman Umum}

a. PAPALELE, Jurnal Penelitian Ilmu Sosial Ekonomi Perikanan dan Kelautan memuat hasil penelitian yang berkaitan dengan bidang sosial ekonomi perikanan dan kelautan.

b. Naskah yang dikirim merupakan karya asli dan belum pernah diterbitkan atau dipublikasikan.

c. Naskah diketik dalam bahasa Indonesia yang baik dan benar, tidak diperkenankan menggunakan singkatan yang tidak umum.

d. Naskah diketik pada kertas A4 dengan menggunakan program microsoft word dengan 2 spasi, margin 2.5 $\mathrm{cm}$ (kiri), $2 \mathrm{~cm}$ (atas), $2 \mathrm{~cm}$ (bawah) dan 1,5 cm (kanan), font 12 times new roman, setiap halaman diberi nomor secara berurutan dengan berkolom 1 (satu), dikirim beserta soft copy maksimal 15 halaman.

e. Naskah dikirim melalui alamat ke redaksi pelaksana PAPALELE, Jurnal Penelitian Ilmu Sosial Ekonomi Perikanan dan Kelautan, Program Studi Sosial Ekonomi Perikanan Jurusan Teknologi Hasil Perikanan, Fakultas Perikanan dan Ilmu Kelautan, Universitas Pattimura, Jln. Mr. Chr. Soplanit Poka-Ambon Telp. (0911) 379859, email: inseijurnal@gmail.com.

\section{Pedoman Penulisan Naskah}

a. Judul tidak lebih dari 15 kata dalam bahasa Indonesia dan bahasa Inggris.

b. Nama lengkap penulis tanpa gelar, penulis korespondensi disertai dengan alamat email.

c. Nama lembaga/institusi disertai alamat lengkap dengan kode pos.

d. Abstrak dalam bahasa Indonesia dan bahasa Inggris tidak lebih dari 200 kata.

e. Kata kunci dalam bahasa Inggris dan Indonesia maksimal 5 kata kunci ditulis dibawah abstrak

f. Pendahuluan, memuat latar belakang, perumusan masalah, keragka teoritis dan tujuan penelitian yang dibuat secara ringkas.

g. Metodologi, memuat lokasi dan waktu penelitian, bagaimana data diperoleh dan sumbernya, bagaimana metode analisis data, jika metode yang digunakan telah diketahui sebelumnya harus dicantumkan acuannya.

h. Hasil dan Pembahasan, memuat suatu topik atau permasalahan yang terkait dengan judul, didukung dengan tabel dan gambar yang dibahas secara komperhensif, dikomplementasikan dengan referensi primer yang mendukung, update dan advance.

i. Kesimpulan dan Saran, memuat pokok-pokok bahasan serta kemampuan mengartikulasi temuan pokok untuk saran yang diberikan.

j. Ucapan terima kasih (bila diperlukan).

k. Daftar Pustaka, dicantumkan dalam naskah bila ada pengutipan dari sumber lain. Proporsi daftar pustaka yang diacu yaitu $80 \%$ merupakan rujukan primer dan $80 \%$ merupakan terbitan 10 tahun terakhir. Disusun berdasarkan abjad, dan penulisan sesuai dengan peraturan yang sudah baku, misalnya:

[KKP] Kementerian Kelautan dan Perikanan. 2012. Statistik Perikanan Tangkap 2011. Direktorat Jenderal Perikanan Tangkap Kementerian Kelautan dan Perikanan

Bataglia P, Romeo T, Consoli P, Scottie G, and Andoloro F. 2010. Characterization of The Artisanal Fishery and Its Socio-Economic aspect in The Central Menditerranean Sea (Aeolian Islands, Italy). Fisheries Research $102: 87-9$.

Pingkan W, Hamzens S, dan Sumardjo. 2007. Strategi Inovasi Sosial Pengembangan Mutu Sumberdaya Manusia Nelayan. Jurnal Penyuluhan Volume 3 Nomor 1.

Fauzi A. dan Anna S. 2005. Pemodelan Sumberdaya Perikanan dan Kelautan. Untuk Analisis Kebijakan. PT. Gramedia Pustaka Utama. Jakarta.

Wibawa T. J, Novianto D, dan Nugroho B. 2012. Sebaran Spasial Kelimpahan Ikan Cakalang (Katsuwonus Pelamis) Berdasarkan Analisis Data Satelit Oseanografi. Prosiding InSINas, 29-30 Nopember 2012.

Muksin D. 2006. Optimalisasi Usaha Perikanan Cakalang (Katsuwonus pelamis) Di Kota Tidore Kepulauan Provinsi Maluku Utara. Tesis. Program Pascasarjana IPB. Bogor.

Syandri H. 2013. Nelayan Cerdas, Nelayan Mandiri. http://www.bunghatta.ac.id/ (diunduh pada 12 September 2013).

1. Tabel, diketik dalam bahasa Indonesia, diberi judul pada bagian atas tabel, diberi nomor urut (tidak dalam bentuk JPEG).

m. Gambar dan grafik, diketik dalam bahasa Indonesia, diberi judul singkat pada bagian gawah gambar dan diberi nomor urut. 
PROGRAM STUDI AGRIBISNIS PERIKANAN

FAKULTAS PERIKANAN DAN ILMU KELAUTAN

UNIVERSITAS PATTIMURA

Jln. Mr. Chr. Soplanit, Poka - Ambon, Maluku Telepon : (0911) 379859

E-mail : inseijurnal@gmail.com

Web : http://ojs.unpatti.ac.id./index.php/insei

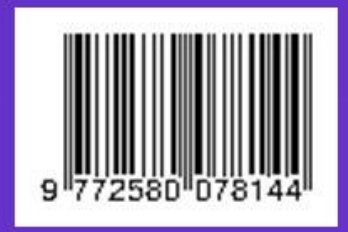

